\title{
EL FOUCAULT DE HABERMAS BAJO SOSPECHA
}

\author{
Mauro Benente* \\ Universidad de Buenos Aires y Universidad de Palermo, Argentina \\ http://dx.doi.org/10.5209/rev_NOMA.2012.v35.n3.42198
}

\begin{abstract}
Resumen.- En el presente trabajo analizaré las críticas esbozadas por Jürgen Habermas a los desarrollos teóricos llevados a cabo por Michel Foucault. Presentaré las referencias que hay hacia Foucault en las distintas obras de Habermas, también las pocas que expone aquél hacia éste, y luego me centraré en El discurso filosófico de la modernidad. En particular, trataré de sugerir que las críticas sólo son aplicables al Foucault que expone Habermas. Postularé que los problemas de Habermas no están en las críticas sino en la presentación que hace del autor francés.
\end{abstract}

Palabras clave.- saber, ciencias humanas, poder, genealogía, modernidad, posmodernidad, razón

\section{Habermas's Foucault under suspicion}

\begin{abstract}
In this piece of work I will analyze the critics raised by Jürgen Habermas to Michel Foucault's theoretical developments. Once having introduced the references to Foucault that Habermas states in different works, the few that Foucault puts forward about Habermas, I will concentrate in The Philosophical Discourse of Modernity. Particularly, I aim to suggest that the critics advanced by the German author can only be applied to the Foucault that Habermas presents. My proposal is that Habermas's problems do not lay in his critics but above all in the presentation he makes of the French thinker.
\end{abstract}

Keywords.- knowledge, human sciences, power, genealogy, modernity, postmodernity, reason

\section{I.- Introducción}

Los trabajos de Habermas muestran una capacidad impresionante de transitar entre diversas tradiciones teóricas y la audacia de dialogar con John Rawls, Jacques Derrida, Karl-Otto Appel y Joseph Ratzinger. En el presente trabajo analizaré las críticas planteadas por Habermas a los desarrollos teóricos llevados a cabo por Michel Foucault. Además de reseñar un breve encuentro que ambos mantuvieron en marzo de 1983 y el proyectado seminario que hubiera tenido lugar

\footnotetext{
* Abogado (Universidad de Buenos Aires), Doctorando en Derecho (Universidad de Buenos Aires), Becario del Consejo Nacional de Investigaciones Científicas y Técnicas, Investigador Adscripto del Instituto "A.L. Gioja". Profesor a cargo del curso "Michel Foucault, el derecho y el poder" en la Facultad de Derecho de la Universidad de Buenos Aires y director del proyecto de investigación DECyT (1207) "El derecho y el poder en y desde Michel Foucault". Docente de "Teoría del Estado" en las Facultades de Derecho de la Universidad de Buenos Aires y de la Universidad de Palermo. maurobenente@yahoo.com
} 
en Estados Unidos en 1984 si la muerte no hubiera sorprendido a Foucault, me centraré en los embates dirigidos por el autor alemán hacia el autor francés.

Presentaré las referencias que hay sobre Foucault en las distintas obras de Habermas, también las pocas que hay de aquél hacia éste, y luego me centraré en El discurso filosófico de la modernidad, en donde es posible hallar muy agudas críticas. Lo que me interesará indagar, además de estas críticas, es el tipo de presentación que hace Habermas de Foucault. En particular, trataré de sugerir que las críticas son sólo son aplicables al Foucault que dibuja Habermas. Según entiendo, gran parte de las críticas que plantea el autor alemán son correctas, pero son únicamente aplicables al Foucault que él expone.

\section{II.- El encuentro y el desencuentro entre Jürgen Habermas y Michel Foucault}

En el mes de marzo de 1983, invitado por el historiador Paul Veyne, Jürgen Habermas pronunció en el Collège una serie de cuatro conferencias, que luego se transformarían en los primeros capítulos de El discurso filosófico de la modernidad, publicado finalmente en 1985. De acuerdo con un relato de Veyne, Foucault no terminó de escuchar ni siquiera la primera de ellas (Eribon, 1994:274). Habermas dictó su primera conferencia durante la mañana del 7 de marzo y por la noche compartió una cena con Paul Veyne, Daniel Defert y Foucault. Luego de este encuentro, Habermas y Foucault no se volvieron a ver ni tuvieron ningún otro intercambio, debate ni discusión.

Es de destacar que en la Universidad de Berkeley, también en el año 1983, se estaba organizando un seminario en el cual discutirían Habermas y Foucault y también estaba prevista la participación de Hubert Dreyfus, Paul Rabinow, Richard Rorty y Charles Taylor. Estaba programado que fuera realizado, al año siguiente. El seminario nunca se hizo puesto que Foucault murió, inesperadamente, el 25 de junio de 1984. En un artículo publicado algunos meses después del deceso y con el título "Apuntar al corazón del presente", Habermas afirmó que el encuentro que finalmente nunca se produjo había sido una iniciativa de Foucault y que la discusión giraría en torno a los doscientos años de la publicación del texto de Kant, “¿Qué es la ilustración?” (Habermas, 1984:119). Con versión, Eribon cita una entrevista con Paul Rabinow en la que el autor norteamericano narra que no fue Foucault quien impulsó la idea de la conferencia, sino que los interesados eran los profesores de la Universidad de Berkeley (Eribon, 1994:290). Sin embargo, en la Universidad de Berkeley en abril de 1983, ya se había desarrollado un interesante entre Foucault, Rabinow, Leo Löwenthal y Martin Jay. Aquel debate, del que también participaron Charles Taylor y Richard Rorty, fue publicado bajo el título de "Politics and Ethics. An Interview" en The Foucault Reader, una compilación realizada por Rabinow en 1984. Allí las referencias a Habermas fueron menores, y Foucault destacó la divergente opinión que tenían de la obra de Heidegger, tema sobre el habían discutido en aquella cena del mes de marzo (Foucault, 1983a:373-374).

Volviendo a aquel artículo escrito después de la muerte de Foucault, Habermas rescata el modo en que el autor francés ubicaba a Kant como el primer filósofo 
preocupado por realizar una ontología del presente, por llevar a cabo una ontología de nosotros mismos, ${ }^{1}$ enmarcándose él mismo dentro de esa tradición. Es a partir del enrolamiento que dentro de esta tradición efectúa Foucault, que el autor alemán se pregunta: “¿cómo encaja tal compresión singularmente afirmativa de la filosofía moderna, siempre dirigida a nuestra actualidad, e inscripta en el aquí y el ahora, con la inflexible crítica foucaultiana a la modernidad? ¿Cómo puede la autocompresión de Foucault como pensador de la tradición del iluminismo ser compatible con su inequívoca crítica a esta forma de conocimiento de la modernidad?" (Habermas, 1984:122). Habermas insiste varias veces en la sorpresa que le ha causado que Foucault se inscribiera dentro de esta tradición kantiana, en esta tradición iluminista y moderna que tantas veces había criticado. ${ }^{2}$ Es así que el artículo se cierra con esta frase: Foucault "[c]ompara su crítica del poder con el «análisis de la verdad» de tal manera que la primera queda privada de los parámetros normativos que debería pedirle al segundo. Tal vez la fuerza de esta contradicción alcanzó a Foucault en el último de sus textos, llevándolo de nuevo al círculo del discurso filosófico de la modernidad que él pensó que podía hacer explotar" (Habermas, 1984:124). En este breve artículo, Habermas recuerda que se había encontrado con Foucault en una única oportunidad, en aquella cena de marzo de 1983, y admite que posiblemente no lo había entendido bien.

Las breves líneas presentes en esta necrológica fueron radicalizadas en un conocido libro de Habermas: El discurso filosófico de la modernidad, publicado en 1985. Lo que resta por analizar es si la incomprensión, también se radicalizó en ese texto. Sin embargo, antes de ello, vale dar cuenta de algunas referencias que realizó sobre Foucault mientras éste se encontraba con vida.

\section{III.- Las referencias de Habermas a Foucault previas a El discurso filosófico de la modernidad}

El discurso filosófico de la modernidad recoge las ya citadas cuatro conferencias que Habermas pronunció en el Collège de France en marzo de 1983, otras dictadas en la Cornell University en septiembre de 1984, y varias ideas que habían sido desarrolladas en un seminario dictado en el Boston College. En el primer capítulo se esbozan algunas líneas sobre la noción de modernidad y aparece la pregunta por la medida en que los autores posmodernos permanecen presos de las premisas de autocomprensión moderna esbozadas en la filosofía de Hegel (Habermas, 1985:15). Por su lado, en los últimos dos capítulos hay una presentación de la teoría de la acción comunicativa y, casi al final, se agrega un contrapunto con los desarrollos de Niklas Luhmann. Cada uno de los restantes capítulos está dedicado a uno o varios autores enrolados bajo una misma

\footnotetext{
${ }^{1}$ Así, y justificando el título de su breve trabajo, Habermas afirmaba que "Foucault descubre en Kant el primer filósofo que, como un arquero, apunta su flecha al corazón de las características más actuales del presente y así abre el discurso de la modernidad" (Habermas, 1984:121).

2 En este orden de ideas se lee: "La filosofía de la historia de Kant, la especulación acerca del estado de libertad, acerca de la ciudadanía del mundo y la paz eterna, la interpretación del entusiasmo revolucionario como signo de histórico «progreso hacia el mejoramiento», ¿no debería provocar en cada línea el desdén de Foucault, el teórico del poder?" (Habermas, 1984:122).
} 
tradición: II) Georg Wilhelm Friedrich Hegel; III) Los hegelianos de izquierda -Karl Marx- y los hegelianos de derecha -Rosenkrantz, Hinrichs y Oppenheim-; IV) Friedrich Nietzsche; V) Max Horkheimer y Theodor Adorno; VI) Martin Heidegger; VII) Jacques Derrida y; VIII) Georges Bataille. Hasta aquí, cada uno de estos autores era acreedor de un capítulo, pero los capítulos nueve y diez están dedicados a un mismo autor: Michel Foucault. Habermas le dedica no uno sino dos capítulos.

Foucault, no ha podido leer esos dos capítulos, pero sí hay referencias de Habermas hacia el autor francés previas a su fallecimiento. Dentro de Perfiles filosófico-políticos, en el artículo dedicado a Alexander Mitscherlich, destaca que el médico y psicólogo alemán ya había criticado el concepto clásico de enfermedad mental mucho antes que el propio Foucault (Habermas, 1978:172) y luego, en el capítulo sobre Herbert Marcuse, a partir de una mención del movimiento antipsiquiátrico, también hay una referencia a Foucault (Habermas, 1973:237). Por su lado, en el primer volumen de Teoría de la acción comunicativa, hay una intrascendente mención de Foucault (Habermas, 1981a:470), y en el segundo tomo, Habermas alude a Foucault como un estructuralista crítico de la modernidad (Habermas 1981b:155). Tal vez Foucault no haya entrado en contacto con estos trabajos. En cualquier caso, las referencias a un Foucault crítico de la noción de enfermedad mental o a un estructuralista crítico de la modernidad son frases con mucho contenido publicitario, pero en la medida en que Habermas no brinda ni siquiera una línea para desarrollar y argumentar semejantes títulos, entiendo que son referencias que no merecerían mayores réplicas.

Sin embargo, es posible que Foucault haya entrado en contacto con un breve trabajo de Habermas titulado "La modernidad: Un proyecto inacabado", la transcripción del discurso que había pronunciado al recibir el premio Adorno en la ciudad de Frankfurt el 11 de setiembre de 1980, que fue publicado prontamente en Francia en Critique - revista en la que a menudo se publicaban entrevistas a Foucault - en octubre de 1981. Allí Habermas distinguía tres tendencias dentro de los trabajos críticos de la modernidad: a- El antimodernismo de los "jóvenes conservadores", que recuperan la experiencia de la modernidad estética y "a la razón instrumental de manera maniquea contraponen un principio sólo accesible a través de la evocación, sea éste la voluntad de poder o soberanía, el Ser o la fuerza Dionisíaca de lo poético. En Francia esta línea va de Georges Bataille, vía Michel Foucault a Derrida" (Habermas, 1980:14); b- el premodernismo de los "viejos conservadores", entre quienes estaban Leo Strauss, Hans Jonas y Robert Spaemann, quienes veían con malos ojos la especialización de la ciencia, del arte y la moral, por lo que recomendaban un retroceso a posiciones premodernas; c- el posmodernismo de las neoconservadores, entre quienes se encontraban el primer Wittgenstein y Carl Schmitt, postulando una separación entre la moral y la política y asumiendo que la ciencia carecía de potencial para orientar las acciones humanas.

Al igual que las referencias anteriores, la mención hacia Foucault es notablemente superficial. Más allá del supuesto objetivo de recuperar la modernidad estética, cuesta encontrar en Foucault esta actitud de contraposición a algo así como la 
razón instrumental. Ésta es una noción trabajada por Weber, la Escuela de Frankfurt y de Habermas, pero no por Foucault. Sin embargo, entiendo aquí se perfila una actitud que Habermas repetirá a menudo: No solamente criticar a los autores sino criticarlos a partir de cosas que nunca escribieron.

Tampoco resulta del todo clara la acusación de "joven conservador." Es cierto que Foucault no tuvo participación política en ningún gobierno revolucionario, no ha sido un férreo militante, pero algunos indicios que creo que sirven para problematizar esta calificación de "conservador". Siendo todavía muy joven, entre 1950 y 1953 Foucault estuvo afiliado al Partido Comunista Francés, aunque nunca fue un militante demasiado activo (Macey, 1993:66-69). Años más tarde, entre 1966 y 1968, mientras trabajaba en Túnez, en un clima de intensas manifestaciones estudiantiles, hospedó en su casa a estudiantes prófugos y escondió un ciclostil con el cual se imprimieron una gran cantidad de panfletos. Asimismo, cuando iniciaron los juicios contra estudiantes detenidos, declaró como testigo y aportó fondos para la defensa de los acusados. Como consecuencia de estos actos, fue amenazado en varias oportunidades y hasta fue golpeado (Macey, 1993:268). Ese mismo año, Foucault retornó a Francia para ocupar la dirección del Departamento de Filosofía del Centro Experimental de Vincennes. Allí, en el mes de enero de 1969, participó de varias tomas del Centro, llevadas a cabo en solidaridad con la represión de protestas estudiantiles, mantuvo enfrentamientos con la policía y quedó detenido durante algunas horas (Eribon, 1989:252-253; Macey, 1993:290-219; Miller, 1993:241).

El 8 de febrero de 1971, la prensa francesa anunciaba la creación del Grupo de Información sobre las Prisiones (GIP), cuya misión radicaba en que los presos pudieran hacer saber el calamitoso funcionamiento del sistema penitenciario. Foucault estaba entre los creadores del grupo y la dirección de correo postal del GIP era el no 285 de la calle Vaugirard, Paris-XVe, es decir, su domicilio. Para esa misma época también participó en la creación de la Agencia de Prensa Libération (Eribon, 1989:310-312; Macey, 1993:387-391). Asimismo, caben destacarse otras actividades políticas: a- en 1971 integró la comisión investigadora del "caso Jaubert", siendo que Alain Jaubert -corresponsal de El nuevo observador $y$ profesor en Vincennes-, había denunciado apremios por parte de la policía; b- en 1972 formó parte de una comisión de protesta por el asesinato, atravesado por cuestiones raciales, de Djellali Ben Alí; c- participó en varias manifestaciones en repudio al asesinato de Mohammed Diab, fusilado en una comisaría de Versailles a fines de noviembre de 1972, y en una de las manifestaciones, la del 16 de diciembre de aquel año, Foucault resultó detenido.

A partir de estos años, Foucault firmó numerosas solicitadas con contenidos políticos, y si bien bajó sus niveles de militancia activa, pueden destacarse varios casos de intervención directa: a- En de septiembre de 1975 el régimen de Francisco Franco había condenado a muerte a dos miembros de la ETA, que se sumaban a otros ocho militantes de la FRAP y, junto con intelectuales y personajes públicos de Francia, viajó a Madrid para expresar su repudio, debiendo abandonar la capital española con custodia policial (Eribon, 1989:324-328; Macey, 1993:419-427); b- En 1977 Klaus Croissant, un abogado de Alemania Occidental 
solicitó asilo en Francia por estar acusado de defender a organizaciones criminales. Mientras tramitaba su solicitud, fue apresado en Paris y se formó un comité luchar por su liberación. Foucault integró el comité, firmó gran cantidad de solicitadas y participó de numerosas marchas, una de las cuales fue reprimida por la policía y sufrió la fractura de una de sus costillas (Eribon, 1989:320); c- En 1980, el mismo año en que Habermas pronunciaba el discurso en el que lo etiquetaba como "joven conservador", participó de la fundación -aunque posiblemente sólo en la fundación- de Defensa Libre, una agrupación cuyo objetivo era denunciar las limitaciones con que se enfrentaban los abogados defensores y las violaciones a los derechos que sufrían quienes estaban acusados ante los tribunales de justicia; d- Entre 1981 y 1982, el sindicado polaco Solidaridad sufrió numerosos episodios de persecución, y Foucault estuvo muy comprometido con actividades de apoyo a la organización sindical.

A partir de estas breves referencias biográficas, si la caracterización de Foucault como conservador era en términos políticos, entiendo que es algo que debería ser mínimamente relativizada. Sin embargo, lo que resulta de mayor interés no son las cuestiones biográficas, sino los elementos teóricos.

Hasta aquí el Foucault de Habermas era un "estructuralista crítico de la modernidad" y un "joven conservador". Habermas nunca fundamentó estos rimbombantes titulares, pero Foucault tampoco se encargo de problematizarlos.

\section{IV.- Las referencias de Foucault a Habermas}

Foucault no ha escrito ningún artículo replicando las acusaciones propinadas por Habermas y es cierto que, a pesar de algunas excepciones, nunca ha estado muy interesado en contestar las críticas que se le efectuaban. Sin embargo, hasta ese entonces las críticas de Habermas no habían sido muy rigurosas y referían a textos de la década de 1960 o 1970, es decir, críticas hacia un Foucault que ya no era el mismo, que había abierto nuevas líneas de reflexión (Eribon, 1994:278-279). Sin embargo, a pesar de la inexistencia de artículos específicos, en el marco de algunas entrevistas se le ha consultado sobre la obra de Habermas y también ha referenciado su obra en algunas conferencias y breves artículos.

En "Sexualidad y soledad", una conferencia de 1981, Foucault sostenía que a partir de la obra de Habermas era posible distinguir tres tipos de técnicas: a- las técnicas que producción, que logran producir, manipular y transformar las cosas; b- las técnicas de significación o comunicación, que permiten emplear los sistemas de signos; c- las técnicas de dominación, que permiten condicionar las conductas individuales. A estas tres técnicas, Foucault agrega aquellas por las cuales el individuo opera sobre su cuerpo, su conducta, sus pensamientos, es decir, las técnicas de sí (Foucault, 1981:989-990). De todos modos, más allá de esta referencia, no hay mayores tratamientos ni sobre obra ni sobre las críticas de Habermas. En 1982, en "El sujeto y el poder", volvió sobre el asunto de las técnicas, y en nota al pie afirmó que "[c]uando Habermas distingue entre dominación, comunicación, y actividad finalizada, no creo que vea en ellos tres dominios separados, sino más bien tres «trascendentales»" (Foucault, 1982a:218). 
También en 1982, pero en una entrevista que le realizó Paul Rabinow, Foucault se refirió nuevamente a la obra del autor alemán. El antropólogo norteamericano le preguntó sobre la recepción de la posmodernidad en la arquitectura y en la filosofía, contexto en el cual Rabinow le nombró los trabajos de Habermas y de Lyotard. Aquí Foucault aseveró que el problema planteado por Habermas apuntaba a señalar que el abandono de la obra de Kant y de Weber implicaba caer en la irracionalidad total, y, con lo que estaba "completamente de acuerdo con eso, pero al mismo tiempo, la problemática es totalmente diferente" (Foucault, 1982b:248-249). Para Foucault la cuestión a resolver radica en saber ¿cuál es la razón que efectivamente utilizamos?, ¿cuáles son sus efectos y consecuencias históricas?, ¿cuáles son los peligros que conlleva esta racionalidad? De algún modo, "si es extremadamente peligroso decir que la Razón es el enemigo que debería ser eliminado, es igualmente peligroso decir que todo cuestionamiento crítico de esta racionalidad corre el riesgo de llevarnos hacia la irracionalidad. Uno no debe olvidar -y no estoy diciendo esto para criticar a la racionalidad, sino para mostrar qué tan ambiguas son las cosas- que el racismo fue formulado sobre la base de la flamante racionalidad del darwinismo social, convirtiéndose en uno de los más duraderos y poderosos ingredientes del nazismo. Esto fue, por supuesto, una irracionalidad, pero una irracionalidad que fue al mismo tiempo una cierta forma de racionalidad" (Foucault, 1982b: 249). Teniendo esto en cuenta, si el pensamiento crítico y la filosofía en general tiene alguna función, no es otra que "aceptar esta suerte de espiral, esta suerte de puerta giratoria de racionalidad que nos remite a su necesidad, a lo que tiene de indispensable, pero al mismo tiempo, a lo que tiene de intrínsecamente peligrosa" (Foucault, 1982b:249). En la misma entrevista, Rabinow le preguntó si temía a las referencias históricas tal como les temía Habermas o si creía que la oposición entre razón e historia no era absolutamente ridícula, y respondió que: "Sí. Bien, el problema de Habermas es, después de todo, realizar un modo trascendental de pensamiento opuesto a todo historicismo" (Foucault, 1982b:250).

Por su lado, en 1983, "Estructuralismo y posestructuralismo", le preguntaron por un elogio que había recibido de Habermas a propósito del modo en que había logrado describir la bifurcación de la razón y el viraje hacia una racionalidad técnica. Foucault, respondió -y quizás aquí pueda leerse algún tipo réplica de aquello que Habermas postulaba en "La modernidad como proyecto inacabado"que "yo no hablaría de una bifurcación de la razón, sino más bien de una bifurcación múltiple, incesante, una suerte de copiosa ramificación. Yo no hablo del momento en que la razón ha devenido técnica" (Foucault, 1983b:1259). Asimismo, y a diferencia de lo que proponía Habermas, entendía que "el chantaje que a menudo se ha ejercido respecto de toda crítica de la razón o de toda interrogación crítica sobre la historia de la racionalidad (o ustedes aceptan la razón, o ustedes caen en la irracionalidad) actúa como si no fuera posible realizar una historia racional de todas las ramificaciones y de todas las bifurcaciones, una historia contingente de la racionalidad" (Foucault, 1983b:1259). También le preguntaron qué opinaba de las críticas de Habermas a la posmodernidad y Foucault contestó no saber "qué era eso de la posmodernidad" (Foucault, 1983b:1265), agregando que "[s]é que los americanos han proyectado una suerte 
de seminario en el que participaría Habermas y estaría yo también. Y sé que Habermas ha propuesto como tema la modernidad. Yo me siento incómodo, porque no veo muy bien lo que quiere decir ni siquiera -poco importa la palabra, uno siempre puede utilizar una etiqueta arbitraria-, cuál es el tipo de problemas que es aludido con esta palabra, o qué sería común a las gentes que se denominan posmodernos" (Foucault, 1983b:1266). Foucault se siente incómodo con la noción de posmodernidad, pero más adelante veremos que el Foucault de Habermas no tiene ningún problema en calzarse ese traje.

Finalmente, en 1984, en "El cuidado de sí como práctica de la libertad", volvió a referirse de modo muy sucinto a la obra de Habermas. Cuando le consultó si en una sociedad en la cual la comunicación funcionara de modo transparente no podría esperarse que los juegos de verdad cobraran independencia respecto de las estructuras de poder, Foucault asoció la pregunta con la obra del autor alemán: "yo me intereso en lo que hace Habermas, sé que no está del todo de acuerdo con lo que yo digo -yo estoy un poco más de acuerdo con lo que él dice-, pero sin embargo hay algo que siempre genera problemas: es cuando él otorga a las relaciones de comunicación ese lugar tan importante y, sobre todo, una función que yo diría «utópica». La idea de que podrá existir un estado de comunicación que sea tal que los juegos de verdad puedan circular en él sin obstáculos, sin coacciones y sin efectos coercitivos me parece del orden de la utopía" (Foucault, 1984:1546). No se trata de disolver las relaciones de poder "en la utopía de una comunicación perfectamente transparente, sino de darse las reglas de derecho, las técnicas de gestión y también la moral, el ethos, la práctica de sí, que permitan, en estos juegos de poder, jugar con el mínimo posible de dominación”. 3 Las referencias de Foucault hacia Habermas son notablemente escasas, pero aun así, se muestran algo más profundas que las, hasta aquí también escasas, de Habermas a Foucault. El autor alemán lo había etiquetado como "joven conservador" y "estructuralista crítico de la modernidad". Foucault no ha etiquetado a Habermas, algunas de sus líneas pueden leerse tanto como reparos respecto de lo que se desprende de "La modernidad como proyecto inacabado", cuanto como defensas a las futuras críticas vertidas en El Discurso filosófico de la modernidad. Foucault, quien no sabe qué es la posmodernidad, no habla de razón técnica o instrumental, sino de las múltiples ramificaciones de la racionalidad, entiende que tan peligroso salirse de la racionalidad como no criticar racionalidades específicas, siendo que las críticas a éstas no implican salirse la racionalidad.

\section{V.- El discurso filosófico de la modernidad}

A riesgo de ser algo reduccionista, podría afirmarse que la apuesta de Habermas a lo largo del trabajo es mostrar que todos los autores que han pretendido escapar a la modernidad y/o a la filosofía del sujeto, han quedado atrapados en alguna de

\footnotetext{
${ }^{3}$ En la misma línea, un año antes, ya había sostenido que "la idea de una política de consenso puede, en determinado momento, servir tanto como principio regulatorio como, mejor aún, de principio crítico con respecto a otras formas políticas; pero yo no creo que eso liquide el problema de la relación de poder" (Foucault, 1983a:378).
} 
las premisas que pretendían desterrar. Es a partir de este diagnóstico que la teoría de la acción comunicativa, si bien no permite evadir las premisas de la modernidad -algo que para no sería posible ni recomendable-, sí permite salir de la filosofía del sujeto, de su problemática actitud objetivante ${ }^{4}$, erradicando así los rasgos totalitarios de una razón instrumental que convierte en objetos a todo lo que la rodea (Habermas, 1985:402). Ahora bien, en lo que sigue, mi intención es repasar, no solamente las críticas de Habermas a Foucault, sino el modo en que presenta la obra del autor francés.

\section{V-a. Las ciencias humanas y la crítica a la razón}

El primer capítulo dedicado a la obra de Foucault se denomina "Foucault: Desenmascaramiento de las ciencias humanas en términos de crítica a la razón". El título ya marca el terreno de modo problemático porque parecería que los análisis de Foucault sobre las ciencias del hombre, se enmarcan dentro, o implican una crítica de la razón. Ya vimos que Foucault se negaba a hablar de la razón en términos genéricos y caracterizaba su propio trabajo como una labor de indagación de racionalidades específicas. En términos bien genéricos, podría afirmarse que en algunos de los trabajos de Foucault hay un estudio sobre las ciencias humanas -en particular sobre su emergencia-, y tal vez hasta una crítica de ellas, pero en el Foucault de Habermas hay una crítica de la razón. Veamos qué argumentos brinda Habermas para postular algo así.

El primer capítulo no solamente tiene un título problemático, sino que además sus primeros párrafos son una serie de frases rimbombantes sin justificación alguna. Habermas lo inicia con una entrevista en la cual Foucault nombra los trabajos de Blanchot, Bataille, Duméziel y Lévi-Strauss, como elementos que han contribuido a construir la idea de desaparición del sujeto, y para Habermas "[e]ste «discurso negativo sobre el sujeto» introducido por Lévi-Strauss, Foucault lo entiende a la vez como una crítica de la modernidad" (Habermas, 1985:286). Lo cierto es que no se explica muy bien de dónde surge que la crítica al sujeto instituyente, es entendida por Foucault como una crítica hacia la modernidad. Creo que correcto el diagnóstico que indica que Foucault quiere desprenderse de cierta filosofía del sujeto, pero ello no implica necesariamente criticar a la modernidad en su conjunto. De hecho Habermas también es un crítico de la filosofía del sujeto pero se siente muy a gusto dentro de la modernidad. Pero además de las influencias de

\footnotetext{
${ }^{4}$ Para Habermas, si presuponemos el modelo de la acción orientada a entendimiento, "aquella actitud objetivante en que el sujeto cognoscente se refiere tanto a sí mismo como a entidades en el mundo, ya no puede gozar de privilegio alguno. En el paradigma del entendimiento intersubjetivo lo fundamental es la actitud realizativa de participantes en la interacción que coordinan sus planes de acción entendiéndose entre sí sobre algo en el mundo. Al ejecutar ego un acto de habla y al tomar alter postura frente a ese acto, ambos entablan una relación interpersonal [...] esta actitud de los participantes es una interacción lingüísticamente mediada permite una relación del sujeto consigo mismo distinta de aquella actitud meramente objetivante que adopta un observador frente a las entidades que le salen al paso en el mundo" (Habermas, 1985:354). Recordemos aquí que "[e]l concepto de entendimiento (Verständigung) remite a un acuerdo racionalmente motivado alcanzado entre los participantes, que se mide por pretensiones de validez susceptibles de crítica." (Habermas, 1981:110).
} 
Bataille y del estructuralismo, para Habermas, Foucault se inscribe dentro de la línea iniciada por Gaston Bachelard, y estas tres tradiciones han dado lugar a Locura y sin razón. Historia de la locura en la época clásica. Para Habermas, y en lo que pareciera ser un título carente no sólo de desarrollo sino ni siquiera de copete, "[l]a pretensión de crítica a la razón queda ya patente en el subtítulo, que reza Historia de la locura en la época clásica, en la época de la razón" (Habermas, 1985:286).

Luego de esta presentación, el autor alemán muestra que en el prefacio de la primera edición de Locura y sin razón (1961), Foucault se proponía trazar una historia de los límites, buscando aquello que la cultura rechaza y transforma en exterior. ${ }^{5}$ La de Habermas, en un texto de 1985, se inscribe en una larga lista de críticas que se le han realizado a Foucault entre 1961 y 1972 sobre la imposibilidad y la paradójica empresa de encontrar la locura en su estado puro, el grado cero de la locura, esa figura de la locura previa a su exclusión por parte de la cultura. Digo entre 1961 y 1972, porque en la edición de este último año Foucault cambió el prefacio de la obra y esa intención fue borrada. Si la hubiera leído, Foucault podría haber estado de acuerdo con esta crítica de Habermas, de hecho, trece años antes, ya había modificado ese prólogo.

Tras esta presentación atravesada por grandes frases sin fundamentar y por una crítica que atrasaba varios años, Habermas se vuelca al análisis de la relación que establece Foucault entre los discursos y las prácticas no discursivas, contexto en el cual plantea, creo que con acierto, que Foucault no termina de explicar el modo en que los discursos se relacionan con las prácticas (Habermas, 1985:291). A Habermas le interesará rescatar la difusa relación que existe determinadas prácticas no discursivas -prácticas de poder-, y determinados discursos -las ciencias humanas-. La primera aclaración que habría que hacer es que aquello que no está bien descripto es cuál es la relación entre prácticas discursivas y no discursivas, algo que ya habían advertido Dreyfus y Rabinow (Dreyfus-Rabinow, 1982:73-100) y no entre discursos y prácticas, porque tal como lo presenta Foucault, el discurso es una práctica (Foucault 1968a, 1968b, 1969). Sin embargo, este no es el punto más problemático de la presentación.

Según entiendo, donde con mayor potencia se encuentra el nexo entre las relaciones de poder y las ciencias humanas es en La verdad y las formas jurídicas y en Vigilar y castigar. En el marco de las conferencias dictadas en mayo de 1973 en Río del Janeiro, Foucault se proponía "mostrar cómo las prácticas sociales pueden llegar a engendrar dominios de saber que no solamente hacen aparecer nuevos objetos, nuevos conceptos, nuevas técnicas, sino también hacen nacer formas totalmente nuevas de sujetos y de sujetos de conocimiento" (Foucault, 1973:1406). En particular le interesaba "mostrar cómo se ha podido formar, en el

\footnotetext{
${ }^{5}$ Allí Foucault entendía que era necesario hacer una historia de la locura de modo que sea posible "encontrar el momento de esta conjuración, antes que ella haya sido definitivamente establecida en el reino de la verdad, antes de que haya sido reanimada por el lirismo de la protesta" (Foucault, 1961:187) y más adelante, en el pasaje que cita Habermas, agrega que "[u]no podría hacer una historia de los límites - de esos gestos oscuros, necesariamente olvidados luego de cumplidos, por los cuales una cultura rechaza algo que será para ella el Exterior-“ (Foucault, 1961:189)
} 
siglo XIX, un determinado saber del hombre, de la individualidad, del individuo normal o anormal, dentro o fuera de la regla, un saber que, en verdad, ha nacido de las prácticas de control y de vigilancia" (Foucault, 1973:1407). Luego de describir las instituciones de secuestro -escuelas, cárceles, hospitales y fábricas-, y el modo en ellas se activan procesos de vigilancia tendientes a adiestrar las fuerzas de los hombres y a transformar su tiempo en tiempo útil, Foucault sugirió que en el marco de estas prácticas de vigilancia, emergió un determinado tipo de saber. Es así que en el marco de estas instituciones de vigilancia se extrae un saber que los mismos individuos producen, por ejemplo al manipular las máquinas o al realizar sus prácticas cotidianas, pero también allí nace "un saber de observación, un saber de algún modo clínico, como el de la psiquiatría, de la psicología, de la psicosociología, de la criminología" (Foucault, 1973:1488). De este modo, el poder disciplinario "ha provocado el nacimiento de una serie de saberes -saber del individuo, de la normalización, saber correctivo- que se multiplicaron en esas instituciones de subpoder, haciendo aparecer las susodichas "ciencias del hombre» y el hombre como objeto de la ciencia" (Foucault, 1973:1490).

En el mismo orden de ideas, en Vigilar y castigar sostenía que el funcionamiento del poder disciplinario dependía de tres mecanismos muy poco sofisticados: a- la vigilancia jerárquica; b- la sanción normalizadora; c- el examen. La práctica del examen está acompañada del registro escrito de las conductas sobre quienes se ejerce el poder y, es a partir de esta escritura, que el examen supone dos consecuencias, que son correlativas entre sí: "la constitución del individuo como objeto descriptible, analizable, [...] para mantenerlo en sus rasgos particulares, en sus aptitudes o capacidades propias, bajo la observación de un saber permanente; y por otra parte la constitución de un sistema comparativo que permite la medida fenómenos globales, de descripción de grupos, la caracterización de hechos colectivos, la estimación de las desviaciones de los individuos los unos en relación con los otros" (Foucault, 1975:192). Tal vez sea posible plantear el problema aristotélico sobre la posibilidad y legitimidad de la ciencia del individuo. No obstante a esta gran cuestión corresponde una respuesta que carece de toda grandeza: “ ¿El nacimiento de las ciencias del hombre? Hay que probablemente buscarlo en esos archivos de poca gloria donde se elaboró el juego moderno de las coerciones sobre los cuerpos, los gestos, los comportamientos" (Foucault, 1975:193).

Hasta aquí lo que desarrolla Foucault, pero el Foucault de Habermas dice otra cosa. En estas instituciones de encierro, "en estas instituciones totales que ponen fin a las cuasinaturales diferenciaciones de la vida viejoeuropea y que convierten el caso excepcional que el internamiento representa, en esa especie de caso normal que representa el internado, ve Foucault los monumentos de la razón reglamentadora" (Habermas, 1985:293). Como bien sabemos, la noción de "instituciones totales" ha sido empleada por Ervin Goffman (1961) y no por Foucault, quien tampoco se ha referido a los monumentos de la "razón reglamentadora", conceptualización que, como ya hemos visto, rechaza explícitamente. A Habermas le interesa "examinar la cuestión de si Foucault logra, en forma de una historia de las ciencias humanas planteada como arqueología y 
ampliada a genealogía, llevar a efecto una crítica radical de la razón, sin verse atrapado en las aporías de esta empresa autorreferencial" (Habermas, 1985:296). Sin embargo, como he tratado de presentar, incluso en los textos en los cuales Foucault propone el nexo más estrecho entre ciencias humanas y relaciones de poder, no hay nada que pueda asemejarse a una crítica de la razón en su totalidad. Incluso asumiendo que Foucault realiza una crítica de las ciencias humanas, de ningún lugar puede extraerse que Foucault intente realizar una crítica a la razón en su totalidad. No obstante, el Foucault de Habermas nos sorprende con muchas otras cosas.

Para Habermas, el proyecto foucaultiano de realizar una historia en términos de anticiencia, se debe a la influencia de la obra de Nietzsche, tal como es posible detectar en la introducción de La arqueología del saber y en "Nietzsche, la genealogía, la historia". Es más, para Habermas, "[e]l contexto político de la recepción de Nietzsche -el desengaño producido por el fracaso de la revuelta de 1968- nos ayuda, ciertamente, a entender biográficamente el concepto de una historia de las ciencias humanas, proyectado en términos de crítica a la razón" (Habermas, 1985:298). Si bien insertarse en el terreno de las explicaciones biográficas resulta notablemente pantanoso, podrían hacerse dos aclaraciones sobre esta supuesta recepción de Nietzsche post mayo de 1968: a- los biógrafos de Foucault, y el propio autor francés han indicado que sus primeras lecturas de Nietzsche datan de 1953 (Eribon, 1989:83-84; Miller, 1993:91-92); y; b- Foucault ya había tematizado sobre la obra de Nietzsche en "Nietzsche, Freud, Marx", la presentación que realizó en el Coloquio Royaumont en 1964 (Foucault, 1964). Además, si hay un libro en el cual hay una profunda indagación sobre las ciencias humanas éste es Las palabras y las cosas, publicado dos años antes del mayo francés.

Sin embargo, para Habermas lo más importante no radica en la recepción de la obra de Nietzsche sino con algo que ya habían marcado Paul Rabinow y Hubert Dreyfus en 1982 (Dreyfus-Rabinow, 1982), pero que Habermas no cita: el giro hacia la teoría del poder, hacia la genealogía, radica en la insuficiencia que presentaba analizar las reglas de formación de los discursos en un plano estrictamente discursivo. Empero aquí no terminan los problemas del proyecto teórico foucaulteano, puesto que "[l]a historia genealógica sólo puede asumir el papel de una crítica a la razón, y en este sentido ser una anticiencia, si logra escapar del horizonte de las ciencias del hombre, de orientación histórica, cuyo hueco humanismo Foucault trata de desenmascarar en términos de una teoría del poder" (Habermas, 1985:299). Como veremos, tampoco terminan los problemas en la presentación que se hace de la obra de Foucault.

\section{$V$-b. El poder como trascendental}

Habermas se muestra interesado en indagar si la genealogía puede asumir el papel de una crítica de la razón, algo que en ningún momento es planteado por Foucault. Sin embargo, vale la pena seguir analizando los pasos del autor alemán, para quien la historia genealógica apunta a: a) Abandonar el presentismo 
característico de la conciencia histórica de la modernidad, es decir no apelar a la búsqueda de un origen, sino a los inicios contingentes; b) Despedirse de la hermenéutica, que Habermas sustenta en pasajes de La arqueología del saber, donde Foucault nunca usa la noción de genealogía; c) Poner fin a cierta historia globalizante y disolver las falsas continuidades.

De estos tres caracteres de la historia genealógica se deriva una nueva modalidad historiográfica, un historicismo que seguirá teniendo componentes trascendentales. Así, Habermas indica que, de este modo de hacer historia "resultan las líneas fundamentales de un historicismo, por así decirlo, trascendental, que a la vez hereda y sobrepuja la crítica que hace Nietzsche al historicismo. La historia radical de Foucault sigue siendo «trascendental» en un sentido débil por cuanto concibe los objetos de la compresión históricohermenéutica del sentido como constituidos -como objetivaciones de una práctica discursiva subyacente en cada caso, a la que hay que aprehender en términos estructuralistas" (Habermas, 1985:302). Quizás este escuro pasaje pueda alumbrarse cuando Habermas parece ver en la obra de Foucault que el poder se erige como un trascendental. Detrás de las azarosas formaciones discursivas, de su constitución, sus desplazamientos y mezclas, el autor francés ubica al poder: "[e]l historiador genealógico explica este ir y venir apelando a innumerables sucesos y a una única hipótesis, a saber: que lo único que perdura es el poder, el cual en el cambio de los procesos de avasallamiento anónimos aparece bajo máscaras siempre nuevas" (Habermas, 1985:303). Luego Habermas insiste sobre este punto, pero incluyendo la supuesta crítica de la razón: "Foucault eleva ahora el «poder» a concepto básico trascendental-historicista de una historiografía planteada en términos de crítica a la razón" (Habermas, 1985:304). Asimismo, dentro de esta línea argumental ubica al poder como una categoría "trascendentalhistoricista", se pregunta por qué utilizar una "tan contaminada categoría de poder [...] por qué Foucault se resolvió a encauzar su teoría de la ciencia, planteada en términos de critica a la razón, por vía de una teoría del poder" (Habermas, 1985:308). Habermas, reitera el motivo biográfico de la recepción de la obra de Nietzsche y las razones internas de la propia obra de Foucault, en particular la sola atención al plano discursivo. En esta línea, el capítulo IX se cierra con la siguiente pregunta: “¿Pero cuáles son entonces las razones que llevan a Foucault a reinterpretar en términos generalizantes como voluntad de poder esta voluntad de saber y verdad, constitutiva de la episteme moderna en general y de las ciencias humanas en particular, y postular que todos los discursos, y de ningún modo sólo los modernos, pueden quedar convictos de un encubierto carácter de poder y de provenir de prácticas de poder?" (Habermas, 1985:317). Este interrogante da pie al capítulo X, titulado "Aporías de la teoría del poder."

Sin embargo, antes de avanzar, es menester plantear algunos reparos sobre lo anterior. En primer lugar, la noción de "voluntad de poder" es ajena el pensamiento de Foucault. En segundo lugar, Foucault tampoco afirma que todos los discursos provienen de prácticas de poder. La atención de Foucault está focalizada en determinados saberes como lo son las ciencias humanas pero no en todos ellos. Finalmente, y nuevamente, es problemático el título del capítulo X. El Foucault de Habermas refiere a una teoría del poder, pero Foucault ha renegado 
sistemáticamente de la pretensión de constituir algo así como una teoría del poder. ${ }^{6}$ Es así que en Historia de la sexualidad I. teniendo los seis volúmenes que estaban proyectados, sostenía que "[l]a apuesta de las investigaciones que van a seguir, es avanzar menos hacia una «teoría» que hacia una «analítica» del poder: quiero decir, hacia la definición del dominio específico que forman las relaciones de poder y la determinación de los instrumentos que permiten analizarlo" (Foucault, 1976a:109). Continuando, y dando algunos motivos por los cuales era preferible referirse a una analítica y no a una teoría, en la entrevista "El juego de Michel Foucault", publicada en julio de 1977, se le preguntó a qué se refería con aquella nueva analítica del poder y Foucault contestó que "[s]i se trata de construir una teoría del poder, se estará siempre obligado a considerarlo como surgiendo de un punto y un momento dado, del que se deberá hacer la génesis, después la deducción. Pero si el poder es en realidad un conjunto abierto, más o menos coordinado (y sin duda más bien mal coordinado) de relaciones, entonces el único problema es de darse una grilla de análisis, que permita una analítica de las relaciones de poder" (Foucault, 1977:302). ${ }^{7}$ Finalmente, en "El sujeto y el poder", se preguntaba si era necesaria una teoría del poder y respondía que aquello que necesitábamos era, no una teoría del poder, sino "una nueva economía de las relaciones de poder" (Foucault, 1982a:210). Según creo, pues, solamente en el Foucault de Habermas hay algo así como una teoría del poder.

\section{V-c. Aporías en la teoría del poder}

A pesar de los rechazos expresos de Foucault y la total ausencia de fundamentos que aporta Habermas para mostrar algo así como una teoría del poder en su obra, entiendo que resulta interesante repasar brevemente cuáles son estas aporías en las que cae el Foucault de Habermas. El capítulo se inicia con algo se lee por tercera vez: los problemas que se generan si se analiza la emergencia de las ciencias humanas teniendo en cuenta únicamente las reglas de formación de los discursos. Es así que gracias a la apoyatura en Dreyfus y Rabinow, Habermas muestra que si bien las reglas pueden mostrar cómo es posible la emergencia de un discurso, no logran explicar el funcionamiento concreto de las prácticas discursivas: "no hay reglas que puedan regular su propia aplicación. Un discurso regido por reglas no puede regular por sí solo el contexto en el que está inserto"

\footnotetext{
${ }^{6}$ Es así que "resulta interesante que El discurso filosófico de la modernidad hable constantemente de una «teoría del poder», allí donde Foucault -sin que exista la obligación de tomar al pie de la letra todo lo que él dice o de ignorar el aspecto estratégico de su autointerpretación- evoca más modestamente «canteras históricas» y evita fijar su definición del poder mediante fórmulas demasiado tajantes" (Cusset-Haber, 2006:26).

7 En la misma línea, en "Diálogo sobre el poder", se negaba a "describir un paradigma de poder" y prefería "señalar la manera en la cual diferentes mecanismos de poder funcionan en nuestra sociedad, entre nosotros, al interior y fuera de nosotros" (Foucault, 1975b:469). Asimismo, en el anteúltimo curso que dictó en el Collège de France, indicó que una de sus líneas de trabajo había sido el análisis de las matrices normativas de comportamiento de los hombres, para lo que había sido necesario realizar un desplazamiento metodológico que "no consistió en analizar el Poder con «P» mayúscula, ni las instituciones de poder o las formas generales o institucionales de dominación, sino en estudiar las técnicas y los procedimientos por los cuales se pretende conducir la conducta de los otros" (Foucault, 1982-1983:6).
} 
(Habermas, 1985:321). De todos modos, Foucault logra escapar a esa dificultad "abandonando la autonomía de las formas de saber y sustituyéndola por una fundamentación en tecnologías de poder, y subordinando la arqueología del saber a una genealogía que explique la emergencia del saber a partir de las prácticas de poder" (Habermas, 1985:321). Luego de reiterar el carácter histórico-trascendental de la categoría de poder, es momento de criticarla por su ambigüedad: "ésta mantiene, por un lado, la inocencia de un concepto utilizable en términos descriptivos y sirve a un análisis empírico de tecnologías de poder [...] Pero por otro, en virtud de la encubierta histórica de su emergencia, la categoría de poder conserva también el sentido de un concepto fundamental pergueñado en términos de teoría de la constitución de la experiencia, que es el que presta al análisis empírico de tecnologías de poder su significado y su carácter de crítica de la razón y asegura a la historiografía genealógica su efecto desenmascarador" (Habermas, 1985:324). Según entiendo, esta ambigüedad marcada por Habermas es muy pertinente, pero solamente válida para el Foucault de Habermas. El análisis sólo tiene sentido si asumimos que en Foucault hay algo así como una categoría denominada poder, que a veces funciona de modo descriptivo y a veces como constitutivo de la experiencia. Ahora, si dejamos de lado el Foucault de Habermas, la ambigüedad no tiene sentido, porque en los trabajos de Foucault no existe algo así como una categoría de poder.

Por otra parte, esta supuesta ambigüedad en la supuesta categoría de poder es lo que para Habermas explica la paradójica asociación entre una actitud positivista y una pretensión crítica. Bajo esta premisa, Habermas comienza una presentación de Vigilar y castigar que, como ya nos tiene acostumbrados, empieza mal, porque data el libro en 1976 y no en 1975 (Habermas, 1985:324). ${ }^{8}$ La presentación empeora cuando se adentra a la descripción del poder en la época clásica, muestra el modo en que lo que importa es la concentración de poder en manos del soberano y la creación de su saber sobre sus súbditos - siendo soberanos y súbditos lenguajes ajenos a los trabajos de Foucault- y concluye que "[e]n todo ello ve ya Foucault los inicios de una biopolítica que se forma gradualmente al abrigo oficial de unos discursos desarrollados en términos jurídicos y referidos a la soberanía del Estado" (Habermas, 1985:325). Aquí, el primer problema a destacar es que la noción de biopolítica no está en la versión de Vigilar y castigar publicada por Foucault. Solamente está en Vigilar y castigar del Foucault de Habermas. En segundo lugar, si tomamos Vigilar y castigar -donde la noción de biopolítica no está- e La voluntad de saber-donde sí se hace presente-, cuesta encontrar que la biopolítica se forme al abrigo de discursos desarrollados en términos jurídicos y con referencia a la soberanía. Más bien, de la lectura del Foucault no habermasiano, surge completamente lo contrario. En Vigilar y castigar, sostiene explícitamente que las disciplinas no son instituidas por el derecho, no son su prolongación en niveles inferiores, sino que directamente son dispositivos "contraderecho" (Foucault, 1975:224). Por su parte, en La voluntad de saber, de modo por demás explícito sostenía que, una de las consecuencias del desarrollo del biopoder "es la importancia creciente tomada por la norma en detrimento del

${ }^{8}$ En la versión en inglés también aparece 1976 como fecha de publicación (Habermas, 1985b:270). 
sistema jurídico de la ley [...] Una sociedad normalizadora es el efecto histórico de una tecnología de poder centrada sobre la vida. En relación con las sociedades que hemos conocido hasta el siglo XVIII, hemos entrado en una fase de regresión de lo jurídico" (Foucault, 1976: 189-190).

Luego, la presentación de Habermas se torna más prolija y se desarrollan algunos caracteres del poder disciplinario, aunque los problemas regresan cuando, luego de postular que las ciencias humanas se encargan de prolongar el efecto normalizador de las disciplinas, entiende que "[l]as ciencias humanas representarían por su propia forma una amalgama de poder y saber -formación de poder y formación de saber constituyen una unidad indisoluble" (Habermas, 1985:326). Ahora bien, si Foucault quisiera demostrar la radicalidad de su planteo, debería demostrar "qué estrategias específicas de poder se transforman en las correspondientes estrategias científicas de objetivación de experiencias tenidas en el contexto de habla cotidiana, prejuzgando con ello el sentido de la utilización de los enunciados teóricos acerca de los ámbitos objetuales así constituidos" (Habermas, 1985:326-327). Como se advierte, la presentación y la acusación de Habermas son bien densas, por lo que merecen un tratamiento detenido.

Es posible afirmar que para Foucault formación de poder y formación de saber representan una unidad indisoluble, aunque tal vez sea una afirmación con demasiado voltaje y sea necesario realizar algunas precisiones. Ya en el resumen del curso Teorías e instituciones penales, indicaba que el saber se encuentra ligado en su funcionamiento y existencia a relaciones de poder y éste no se ejerce sin la extracción de un determinado tipo de saber (Foucault, 1972a:1257-1258). Del mismo modo, además de lo ya reseñado sobre la emergencia de las ciencias humanas en La verdad y las formas jurídicas y en Vigilar y castigar, vale destacar que en "Hay que defender la sociedad" indicaba que "el poder, cuando se ejerce en sus mecanismos finos, no puede hacerlo sin la formación, la organización y la puesta en circulación de un saber, o más bien, de aparatos de saber" (Foucault, 1975-1976:30). En la misma línea, y bajo la idea de una regla de la inmanencia, en Historia de la sexualidad I proponía entender que entre las técnicas de saber y las estrategias de poder no había ninguna exterioridad, puesto que las relaciones de poder no se asentaban sobre un saber desinteresado (Foucault, 1976a:130). Teniendo esto en cuenta, creo que Foucault está proponiendo algo menos poderoso que lo que sugiere Habermas. No es que formación de poder y formación de saber representan una unidad indisoluble, sino que las relaciones de poder necesitan para su funcionamiento de saberes, que a su vez, coadyuvan a que esas relaciones sigan actuando. Si bien esto puede resultar un pequeño matiz, entiendo que es más problemática la afirmación habermasiana según la cual las ciencias humanas son una amalgama de saber y poder, afirmación a la luz de la cual debe leerse la idea de indisolubilidad. Según creo, y por oposición a la lectura que hace Habermas, las ciencias humanas, son saberes -o están inscriptas en un determinado orden de saber, para usar una terminología más cercana a Las palabras y las cosas-. No son un híbrido de saber y poder. Son saberes que se constituyen como tales en el marco de prácticas de poder, pero no por ello pierden su status de saber. En este orden de ideas, en "Estructuralismo y posestructuralismo" a Foucault se le preguntó por la tesis según la cual la "razón 
es poder" y contestó: "Comprendo bien que esto forma parte del destino de todos los problemas, de envilecerse en slogans. Nadie ha dicho: «La razón es el poder», yo creo que nadie ha dicho que el saber era un poder" (Foucault, 1983b:1273). Se le replicó que estas cosas "se han dicho" y Foucault continuó: "se ha dicho, pero, usted comprenda, cuando leo -y sé muy bien que se me atribuye- la tesis «el saber es el poder» o «el poder es el saber», poco importa, yo estallo de risa, puesto que precisamente mi problema es estudiar sus relaciones; si fueran dos cosas idénticas, yo no tendría que estudiar sus relaciones y me fatigaría mucho menos. El solo hecho de que plantee la cuestión de sus relaciones prueba bien que no los identifico" (Foucault, 1983b:1273-1274).

Si lo anterior es correcto, carece de sentido probar, tal como reclama Habermas, que las estrategias de poder se transforman en estrategias científicas de objetivación. No es el saber mismo el que tiene una cuota de poder, sino que como bien apunta la regla de la inmanencia -y como luego lo confirma Foucault en la citada entrevista-, entre saberes y poder hay una íntima relación, pero no por ello se confunden. Frente al planteo de Habermas, sólo cabe, pues, la risa.

Ahora bien, luego de esta problemática presentación de Vigilar y castigar y de aquel denso pasaje, Habermas vuelve sobre un supuesto doble papel, "irritante", de la genealogía de las ciencias humanas: por un lado un papel empírico de análisis de las tecnologías de poder y de la emergencia del saber científico y, por otro lado, un papel trascendental "cuyo fin es explicar cómo son en general posibles los discursos científicos sobre el hombre. Las relaciones de poder interesan aquí como condiciones de constitución del saber científico" (Habermas, 1985:328). Asimismo, en tanto la historiografía genealógica pretende cumplir ambos papeles de modo simultáneo, es que "[e]n su concepto de poder Foucault forzó una fusión de la noción idealista de síntesis trascendental y de los supuestos de una ontología empirista" (Habermas, 1985:328). Nuevamente el diagnóstico del autor alemán es bien profundo, pero muy problemático. Es cierto que Foucault apela a un papel empírico de las relaciones de poder, y aquí podrían caberle los mismos problemas que a cualquier positivista. Sin embargo, resulta problemático pensar en un papel trascendental. En primer lugar porque a Foucault no le interesa explicar "en general" las condiciones de posibilidad del conocimiento científico. Quien gusta de explicar las cosas "en general" es Habermas, quien por ejemplo ha intentado constituir algo así como una "pragmática universal", pero este no es el registro en el que escribe Foucault. Tampoco estas investigaciones se inscriben dentro de una línea con estilo kantiano. La pregunta no es: "¿cuáles son las condiciones de posibilidad, necesarias, formales y universales de emergencia de las ciencias del hombre?", por lo que no hay un papel trascendental de la historia genealógica. Ésta se inscribe en un registro más bien empírico que se pregunta por -y reitero una referencia de La verdad y las formas jurídicas- "cómo se ha podido formar, en el siglo XIX, un determinado saber del hombre, de la individualidad, del individuo normal o anormal, dentro o fuera de la regla, un saber que, en verdad, ha nacido de las prácticas de control y de vigilancia" (Foucault, 1973:1407). No hay una pregunta por el saber científico "en general", tampoco una preocupación por sus condiciones de constitución, ni mucho menos por "la constitución de los objetos de la experiencia" (Habermas, 
1985:328). Estas preguntas, estas preocupaciones, están solamente en el Foucault de Habermas.

Por otra parte, para Habermas, Foucault puede sentirse un "positivista feliz" porque: a- desplaza la comprensión del intérprete por la explicación de discursos; b- reduce las pretensiones de validez a efectos de poder; c- reduce el "debes" a términos naturalistas del "es". Es así que Foucault no logra explicar en qué términos hay que concebir la labor del historiador genealógico y la "presunta objetividad del conocimiento se ve entonces puesta en cuestión: 1) por el involuntario presentismo de una historiografía que permanece ligada a su situación de partida; 2) por el inevitable relativismo de un análisis referido al presente que ya sólo puede entenderse a sí mismo como una empresa práctica dependiente del contexto; y 3) por el arbitrario partidismo de una crítica que no puede dar razón a sus fundamentos normativos. Foucault es lo suficientemente insobornable como para confesar estas inconsistencias" (Habermas, 1985:331).

Respecto de la primera supuesta inconsistencia, se lee que "Foucault quiere eliminar, como hemos dicho, la problemática hermenéutica y con ella aquella autorreferencialidad que se pone en marcha con el acceso, en términos de compresión, al ámbito objetual" (Habermas, 1985:331). El historiador genealógico no debe proceder, al estilo de un hermeneuta, intentando comprender aquello que los actores sociales interpretan de sus propias prácticas, sino que debe acercarse a ellas aprehenderlas en su estructura, para lo cual no necesita de ninguna precomprensión hermenéutica. Empero, a pesar de este proclamado objetivismo, Habermas entiende que no es posible explicar las tecnologías de poder sin compararlas entre sí, siendo inevitable que las comparaciones se realicen desde la situación hermenéutica en la que se halla el intérprete. De este modo, Foucault se encuentre frente a "la aporía de un procedimiento que quiere ser objetivista y que a la vez no puede menos que constituir un diagnóstico de nuestro tiempo" (Habermas, 1985:333). Según entiendo, la inconsistencia que advierte Habermas es correcta pero, como es habitual, sólo válida para el Foucault de Habermas. El autor alemán no explica dónde se encuentra esta supuesta pretensión de objetividad. De hecho, las pocas referencias que el autor francés realiza sobre la objetividad, son para desecharla. Así, en "Nietzsche, la genealogía y la historia", reivindica la noción de nietzscheana de Herkunft [procedencia], se opone a la pretensión de objetividad del discurso científico (Foucault, 1971:1010). Asimismo, la genealogía, o la "historia efectiva", se enfrentan a la pretensión de objetividad de la historia de los historiadores (Foucault, 1971:1014, 1019). No sabemos muy bien, dónde ha leído Habermas esta pretensión de objetividad, pero sí sabemos que una de las pocas veces que Foucault se refirió a ella, ha sido para oponérsele.

En segundo lugar, Habermas indica que no son claras las pretensiones de validez de la historiografía genealógica, puesto que con su historia genealógica, Foucault intenta "poner en marcha una ciencia que sea superior a las desprestigiadas ciencias humanas" (Habermas, 1985:334). Valiéndose de la primera clase del curso "Hay que defender la sociedad", Habermas postula que la genealogía intenta hacer emerger los saberes locales y marginales que han sido históricamente descalificados. Trata de recuperar los discursos que resisten a las 
prácticas de poder y "[d]esde esta posición de contrapoder se hace de una perspectiva que iría más allá de las perspectivas de los que en cada caso ostentan el poder" (Habermas, 1985:335). Ahora bien, el problema que agudamente identifica Habermas es que si un contrapoder se alza con la victoria se convierte en un poder que, a su vez, provocará otro contrapoder, en proceso circular que no es posible detener. Es por ello que Foucault "no puede reclamar para su saber ninguna superioridad basada en pretensiones de validez que trascienden los convenios locales" (Habermas, 1985:336). Foucault se percata de esta situación aporética, pero prefiere escapar a la situación reivindicando un perspectivismo al estilo de Nietzsche. Nuevamente, la inconsistencia detectada por Habermas es interesante, pero el problema es que Foucault en ningún momento reclama para la historia genealógica un status de superioridad respecto de las desprestigiadas ciencias humanas. Además, no solamente asume su perspectivismo (Foucault, 1973:1419), sino que tampoco tendría problemas en suscribir esa circularidad entre poderes y contrapoderes, pero aquello que Foucault en ningún momento afirma -ni Habermas da pistas de dónde hallar argumentos en esta línea- es la pretensión de superioridad de la historia genealógica respecto de las ciencias humanas. En "Hay que defender la sociedad", desde donde se asienta Habermas para desarrollar sus argumentos, Foucault caracteriza a los saberes sometidos a partir de dos elementos: a- se trata de saberes históricos que han sido sepultados o incluidos en sistematizaciones formales; b- se trata de saberes que fueron descalificados como tales, inferiores a la cientificidad exigida. La genealogía, pues, tiene como misión hacer emerger esos saberes sometidos. De lo que se trata es de "hacer actuar los saberes locales, discontinuos, descalificados, no legítimos, contra la instancia teórica unitaria que pretendería filtrarlos, jerarquizarlos, ordenarlos en nombre de un conocimiento verdadero, en nombre de los derechos de una ciencia que estaría poseída por algunos [...] Las genealogías son, muy exactamente, anticiencias. No porque ella reivindique el derecho lírico a la ignorancia y el no saber; no se trata de rechazar el saber o de la puesta en juego, de la puesta de manifiesto de prestigios de una experiencia inmediata, todavía no capturada por el saber. No es de eso de lo que se trata. Se trata de la insurrección de los saberes. No tanto contra los contenidos, los métodos o los conceptos de una ciencia, sino de una insurrección, en primer lugar y ante todo, contra los efectos de poder centralizadores que están vinculados a la institución y al funcionamiento de un discurso científico organizado al interior de una sociedad como la nuestra" (Foucault, 1975-1976:10). En ningún momento la apuesta es constituir un saber superior al de las ciencias humanas, sino que lo que está en juego es hacer actuar a los saberes locales sin caer en el poder centralizador del discurso de la ciencia. Asimismo, y a diferencia de lo que asumía Habermas anteriormente, la idea de anticiencia no es asimilable a una crítica a la razón en su totalidad, sino a la pretensión totalizadora de la ciencia, que no son cosas equivalentes.

La pretensión de constituir un saber superior al de las ciencias humanas, está solamente en el Foucault de Habermas. Sin embargo Habermas no solamente hace una presentación sumamente problemática de los desarrollos de Foucault, sino que además él mismo se vuelve inconsistente: a) Por un lado Habermas le 
adjudica a Foucault una supuesta pretensión de objetividad y a partir de allí le critica la imposibilidad de lograr tal cometido. b) Ahora bien, pocas páginas más adelante, el propio Habermas caracteriza a Foucault ya no como una objetivista sino como un perspectivista, algo que invalidaría la acusación vertida en el punto (a). Aquí ya no solamente estamos ante el Foucault de Habermas, sino ante los diferentes Foucaults de Habermas, algo que se reiterará, tal como mostraré, en trabajos posteriores a El discurso filosófico de la modernidad, en los cuales Habermas etiquetará a Foucault como estructuralista y luego como posestructuralista.

Finalmente, Habermas se pregunta si Foucault logra escapar del criptonormativismo, de la actitud de apoyarse en valores, pero sin revelarlos o asumirlos (Voirol, 2006:128). Para Habermas, "la historia genealógica pone entre paréntesis las pretensiones de validez normativa al igual que hizo con las pretensiones de validez proposicional, y se abstiene de preguntar si algunas formaciones de discurso y poder podrían acaso estar más justificadas que otras. Foucault se resiste a la exigencia de tomar partido" (Habermas, 1985:337). No obstante, para Habermas, esta neutralidad valorativa proclamada no es tal, puesto que la actitud crítica domina toda la obra de Foucault. Valiéndose de un famoso artículo de Nancy Fraser, Habermas se pregunta, frente a los diagnósticos de Foucault, ¿por qué hay que oponerse a las relaciones de dominación? ¿Por qué es preferible la rebelión que la sumisión? y postula que estas preguntas sólo pueden ser respondidas en tanto y en cuanto introduzcamos nociones normativas (Fraser, 1981). El problema radica en que Foucault "no tiene más remedio que abstenerse también de dar respuesta a la cuestión de los fundamentos normativos de su crítica" (Habermas, 1985:342).

Según entiendo, Habermas parte de la idea según la cual sólo puede desarrollarse una crítica partiendo de determinados fundamentos normativos (Santana PérezPérez Rodríguez, 1999:113). La pregunta que Habermas le plantea a Foucault es si "practica una filosofía social crítica a la que se le puedan asociar principios al mismo tiempo sólidos, pertinentes y coherentes entre sí" (Cusset-Haber, 2006:17). Según entiendo, la referencia resume de modo muy adecuado uno de los testeos a los que es sometida la obra de Foucault. Sin embargo, el testeto está mal planteado puesto que Foucault no tiene ninguna intención de desarrollar algo así como una filosofía social crítica ni mucho menos "socavar la modernidad y sus juegos de lenguaje" (Habermas, 1985:338). A Foucault le interesa el análisis de prácticas y racionalidades específicas. Ahora bien, aun teniendo en claro que su interés se concentra en el estudio de las prácticas específicas y sus desarrollos conceptuales implican hipótesis de corto alcance, la pregunta de Fraser que rescata Habermas sigue presente. En la obra del autor alemán, la crítica tiene un anclaje bien marcado, puesto que la constitución de la pragmática universal le permite analizar en qué medida se cumplen o se distorsionan las acciones orientadas al entendimiento y hasta qué punto, en el momento de la argumentación racional intersubjetiva, intervienen otras variables que desfiguran la premisa según la cual los actores se ajustan y consienten el mejor argumento. Es por esto que "la crítica no es arbitraria, pues permite dar cuenta del punto de vista 
práctico a partir del cual somete a denuncia las evoluciones problemáticas del tiempo presente" (Voirol, 2006:130).

Ahora bien, en el caso de Foucault la situación es más compleja puesto que no es fácil desarrollar una crítica cuando las pretensiones de validez normativas no se esgrimen en términos universales. Sin embargo, reconociendo esta problemática, entiendo que es menester realizar algunas precisiones. En primer lugar, al menos en sus libros y cursos, no es claro que Foucault esté realizando una crítica de los dispositivos de poder, de las relaciones de poder que se desarrollan en los dispositivos disciplinarios. Me parece que más que una crítica, se trata de una descripción. ${ }^{9}$ En segundo lugar, entiendo que así como no hay estrictamente una crítica, tampoco hay algo así como un deber de rebelarse ante los dispositivos. Por su lado, además de rechazar la posición del intelectual que habla en lugar de los otros y les propone una receta de rebelión (Foucault, 1972b), entiendo que Foucault era consciente que los intelectuales no podían definir cuál podría llegar a ser el alcance de sus trabajos, incluso cuándo quisieran proponérselo. Es así que cuando le preguntó para qué tipo de luchas podían servir sus publicaciones, Foucault contestó: "mi discurso es evidentemente un discurso de intelectual, y, como tal, funciona dentro de las redes de poder establecidas. Pero un libro es realizado para servir a usos no definidos por quien lo escribe. Cuantos más usos nuevos, posibles e imprevistos haya, más contento estaré. Todos mis libros, sea Historia de la locura o ése [se refiere a Vigilar y castigar] son, si usted quiere, pequeñas cajas de herramientas. Si las gentes quieren abrirlas, servirse de tal frase, tal idea, tal análisis como de un destornillador o de una llave para cortocircuitar, descalificar, romper los sistemas de poder, incluidos, eventualmente, aquellos de los cuales mis libros provienen... ipues bien, tanto mejor!" (Foucault, 1975c:1588). El "tanto mejor", pues, me parece que no tiene los fundamentos normativos que le gustarían a Habermas, pero habría que discutir hasta qué punto son necesarios. También, aunque esto sería objeto de otro artículo, cabría analizar si el calificativo de arbitrariedad que se le adjudica a los juicios que no hacen explícitos los fundamentos normativos, no debe ser aplicado a la elección misma -más allá de su explicitación- de los fundamentos normativos. La pregunta sería, aunque la respuesta quede para otro momento, si la explicitación de los fundamentos normativos borra su dosis de arbitrariedad.

Para finalizar el capítulo, Habermas realiza un pequeño desplazamiento, puesto que se avoca a dar cuanta de algunos problemas que el método genealógico imprime en las investigaciones empíricas. En primer lugar, sostiene que si solamente estamos frente a confrontaciones entre cuerpos y contextos de acción estratégica, y si excluimos las normas y los valores sin remplazarlos por un sustituto funcional, no es posible explicar la "cuestión de cómo es en general posible un orden social” (Habermas, 1985:342). Aquí, nuevamente la crítica de Habermas podría llegar a ser correcta si en Foucault existiera una pretensión de explicar en general el orden social. Nuevamente, el error no está en la crítica sino

\footnotetext{
${ }^{9}$ En este sentido, mostrando los problemas que acarrean no articular los diagnósticos de Foucault con una teoría de la explotación, Legrand destaca que las noción de disciplina no es mala en sí misma, así como las prácticas de sí tampoco son buenas en sí mismas (Legrand, 2004:27).
} 
en suponer que Foucault tiene la pretensión de explicar el orden social en general. Nunca ha intentado explicar nada en general, y los trabajos genealógicos que cita Habermas, Vigilar y castigar e Historia de la sexualidad, están bien delimitados en el objeto de estudio: en el primer caso la emergencia instituciones disciplinarias en Francia en los siglos XVII, XVIII y XIX y, en el segundo caso, una introducción a investigaciones - nunca publicadas- sobre la emergencia de un poder productor de discursos verdaderos sobre el sexo en Europa, en mismo siglos. De ningún modo hay una reflexión sobre el orden social en su conjunto ni, mucho menos, la pretensión de explicar, en general, cómo es posible el orden social. Tras esta errónea presentación, el autor alemán avanza sobre dos críticas empíricas: una sobre la genealogía del derecho penal moderno y la otra sobre la sexualidad. Me concentraré sobre la primera de las críticas, porque la segunda, me parece tan imprecisa que, lamentablemente, no logro ni reproducirla.

Una vez más, la presentación es incorrecta puesto que Foucault no hace una genealogía del derecho penal, sino una genealogía del nacimiento de la prisión, como el subtítulo de Vigilar y castigar indica, y para explicarlo es menester incluirla dentro de una tecnología general del poder sobre los cuerpos, y no dentro del ámbito del derecho penal. Sin embargo, Habermas sigue embarrándose cuando indica que "la historia de la justicia penal moderna pueda quedar disociada de la evolución del Estado de derecho, es algo que quizás pueda todavía justificarse haciendo referencia a técnicas de exposición. Pero lo que ya no es de recibo es que la teoría sólo tenga el sistema de ejecución de la penas. En cuanto pasa de la época clásica a la modernidad, Foucault ya no presta atención alguna al derecho penal y al derecho procesal penal" (Habermas, 1985:346). Entiendo que si Foucault intentara desarrollar una historia de la justicia penal moderna, los reproches serían muy atendibles. Sin embargo la focalización ha estado en el nacimiento de la prisión, en la ejecución de la pena, no en la justicia penal en su totalidad, ni mucho menos en el derecho procesal penal.

De acuerdo con Habermas, Foucault indica que detrás de las modificaciones en el discurso moral y jurídico sobre el castigo no hay otra cosa que una mutación en las tecnologías de poder. Es así que "Foucault puede ilustrar esta tesis con ejemplos impresionantes; sin embargo, cuando se la generaliza, la tesis es falsa. Pues entonces viene a decir que el panoptismo que puede constatarse en la moderna ejecución de las penas es característico de la estructura de la modernización social en su conjunto. Foucault sólo puede plantear esta tesis generalizada porque se está moviendo en unas categorías de teoría del poder a las que escapan las estructuras normativas de la evolución del derecho" (Habermas, 1985:345). Aquí no queda del todo claro a qué tipo de generalización se refiere Habermas, pero para afirmar que diseño arquitectónico del panóptico fue aplicado en cárceles, escuelas y hospitales y, en Vigilar y castigar, Foucault acompaña planos de estas instituciones. Además, el propio Bentham -tanto en las cartas escritas en Rusia cuanto en la publicación confeccionada por Garran de Coulon- sostenía que el modelo del panóptico servía para una prisión, pero también para casas de corrección, hospitales, fábricas y escuelas (Bentham, 1787:76-95; 2004:283-284). Cuesta desentrañar a qué refiere Habermas con esta 
generalización, pero cuando Foucault no circunscribe el diseño panóptico a la prisión, tampoco lo hacía Bentham, lo hace con sustento histórico.

\section{$V$ - d. Balance de El discurso filosófico de la modernidad}

A modo de balance, y a excepción del criptonormativismo, diagnóstico que adquiere mayor validez con las reglas del juego que propone Habermas que para las (pocas) que esgrime Foucault, entiendo que las críticas sólo son adecuadas para el Foucault de Habermas. Según creo, los embates del autor alemán en muchos casos son correctos, pero lo que está en discusión no es el embate sino la presentación del autor francés que, a mi modo de ver, es sumamente problemática.

Por otra parte, en trabajos posteriores a El discurso filosófico de la modernidad, las referencias de Habermas hacia Foucault serán menos problemáticas porque serán, tal como lo eran antes de este trabajo, considerablemente superficiales. Sin embargo, es posible advertir cómo Habermas lo ubica, en diversas obras, bajo diferentes rótulos

\section{VI.- Después de El discurso filosófico de la modernidad. Foucault estructuralista, posestructuralista y posmoderno.}

Con posterioridad a El discurso filosófico de la modernidad, las referencias de Habermas a Foucault volvieron a ser superficiales, como lo habían sido hasta ese entonces. En "Heidegger: obra y visión del mundo" preparado para prologar el libro Heidegger y el nazismo, sin mayor desarrollo -aunque podríamos llegar a compartir algo de esto-, Habermas incluye a Foucault dentro de los autores franceses que han sido influenciados por la crítica heideggeriana a la razón (Habermas, 1988a:60). Por su lado, en Pensamiento postmetafísico, alude en varias oportunidades a Foucault. En el primer capítulo lo menciona al pasar (Habermas, 1988b:15), más adelante reseña muy brevemente la última parte de Las palabras y las cosas, en donde Foucault muestra que las ciencias humanas habían quedado atrapadas dentro de una doble perspectiva empíricotrascendental (Habermas, 1988b:51) y luego lo nombra, también al pasar, en otras cinco oportunidades (Habermas, 1988b:106, 188, 247, 272, 274). Sólo dentro del capítulo noveno, “¿Filosofía y ciencia como literatura?", es posible encontrar referencias más precisas. Aquí, ya no alude a Foucault como un estructuralista, algo que había realizado en Teoría de la acción comunicativa, sino que lo etiqueta como posestructuralista para quien "todas las pretensiones de validez se tornan inmanentes al discurso, y quedan simultáneamente absorbidas en el todo del ciego acontecer de discursos y entregadas al «juego de azar» de su recíproco sobrepujamiento. Esta concepción exige "sacrificar al sujeto cognoscente» y sustituye a la ciencia por genealogía" (Habermas, 1988b:244).

En Facticidad y Validez hay una mención superficial a Foucault dentro de una referencia al estructuralismo, en cuya tradición se encontraría inmerso el autor francés (Habermas, 1992:111), siendo que antes lo había incluido dentro del 
posestructuralismo. Por su lado, en "Una vez más: Sobre la relación entre teoría y praxis", incluido en Verdad y justificación, también de modo superficial, Habermas incluye a Foucault junto con Karl-Otto Appel, Hans Blumenberg, Jacques Derrida y Richard Rorty, dentro de un grupo de autores posmodernos críticos de la modernidad (Habermas, 1999:312). Ahora el Foucault de Habermas ya no sólo oscila entre el estructuralismo y el posestructuralismo, sino que tiene un traje de posmoderno, traje con el que Foucault, ya sabemos, no se sentía muy cómodo. Finalmente, en "¿Tiene todavía alguna posibilidad la constitucionalización del derecho internacional?", un artículo dedicado a la constitucionalización del derecho internacional desde una mirada kantiana, se notan ciertos peligros que Foucault advierte en la normalización (Habermas, 2004:126).

\section{VII.- Notas finales}

Jürgen Habermas es quizás uno de los autores más importantes de la filosofía política y social contemporánea, y ha tenido la capacidad de entablar diálogo con numerosas tradiciones teóricas. De hecho, la fotografía de sus textos indica una notable capacidad para presentar autores, marcar sus deficiencias y hacer los ajustes pertinentes para que el andamiaje teórico a proponer se encuentre más sólido.

En el presente trabajo tenía la intención de reconstruir algo así como una gigantomaquía. Un gigante del siglo XX como Michel Foucault frente -o a los ojosde otro gigante como Jürgen Habermas. Sin embargo, el problema con el que me encontré es que las críticas que efectuaba Habermas se referían a un Foucault muy distinto al que estaba acostumbrado a leer. La sensación final, luego de recorrer y analizar en varias oportunidades los trabajos de Habermas, es la imposibilidad de reconstruir esa gigantomaquia, puesto que el Foucault de Habermas dista mucho de ese gigante del siglo XX.

\section{VII.- Bibliografía}

BENTHAM, Jeremy (1787) "Panopticon, or, The inspection-house". en The Panopticon Writings (ed. by Miran Bozovic), Verso, New York 1995, pp 31-95.

(2004), "Panóptico" (trad. de R. Salas). En Tratados de legislación civil y penal VII, Tribunal Superior de Justicia del Distrito Federal, México DF, pp 201-284. 
CUSSET, Yves, HABER, Stéphane (2006) "Introducción. Las coordenadas del debate entre Foucault y Habermas" (tr de H. Cardoso). En CUSSET, Yves, HABER, Stéphane, Habermas y Foucault. Trayectorias cruzadas, confrontaciones críticas, Nueva Visión, Buenos Aires, 2007, pp 11-31.

DREYFUS, Hubert, RABINOW, Paul (1982) Michel Foucault: Beyond Structuralism and Hermeneutics, The University of Chicago Press, Chicago, 1983.

ERIBON, Didier (1989) Michel Foucault (tr. de T. Kauf), Anagrama, Barcelona, 1992.

(1994) Michel Foucault y sus contemporáneos (tr de Viviana Ackerman), Nueva Visión, Buenos Aires, 1995.

FOUCAULT, Michel (1961) "Préface". En Dits et écrits I, Gallimard, Paris, 2001, nº 4, pp 187-195.

(1964) "Nietzsche, Freud, Marx". En AA. VV., Colloque de Royaumont, Les éditions minuit, Paris, 1967, pp. 183-200.

(1968a) "Réponse à une question”. En Dits et écrits, Gallimard, Paris, 2001, n ํ58, pp 701-723.

(1968b) “Sur l'archéologie des sciences. Réponse au Cercle d’épistémologie”. En Dits et écrits I, Gallimard, Paris, 2001, nº 59, pp 724-759.

(1969) L'archéologie du savoir, Gallimard, Paris.

(1972a) “Théories et institutions pénales". En Dits et écrits I, Gallimard, Paris, 2001, no 115, pp 1257-1261.

(1972b) "Les intellectuels et le pouvoir". En Dits et écrits I, Gallimard, Paris, 2001, no 106, pp 1174-1183.

(1973) "Le vérité et les formes juridiques". En Dits et écrits I, Gallimard, Paris, 2001, no 139, pp 1406-1514.

(1975) Surveiller et punir. Naissance de la prison. Gallimard, Paris.

(1975b) "Dialogue sur le pouvoir". En Dits et écrits II, Gallimard, Paris, 2001, no 221, pp 464-477.

(1975c) "Des supplices aux cellules" en Dits et écrits I. Paris: Gallimard, 2001, nº 151, pp 1584-1588.

(1975-1976) «ll faut défendre la société», Gallimard-Seuil, Paris, 1997.

(1976) Histoire de la sexualité I. La volonté de savoir. Gallimard, Paris.

(1977) “Le jeu de Michel Foucault". En Dits et écrits II, Gallimard, Paris, 2001, nº 206, pp 298-329.

(1981) "Sexualité et solitude". En Dits et écrits II, Gallimard, Paris, 2001, no 295, pp 987-997. 
(1982a) "The Subject and Power". En DREYFUS, Hubert, RABINOW, Paul, Michel Foucault: Beyond Structuralism and Hermeneutics., The University of Chicago Press, Chicago, 1983, pp. 208-226.

(1982b) "Space, Knowledge, and Power". En RABINOW, Paul (Ed.) The Foucault reader, Pantheon Books, New York, 1984, pp 239-256.

(1982-1983) Le gouvernement de soi et des autres, Paris: Gallimard, 2008.

(1983a) "Politics and Ethics: An Interview". En Rabinow, Paul (Ed.) The Foucault reader, Pantheon Books, New York, 1984, pp 373-380.

(1983b), "Structuralisme et poststructuralisme". En Dits et écrits II, Gallimard, Paris, 2001, no 330, pp 1250-1276.

(1984) "L'éthique du souci de soi comme pratique de la liberté". En Dits et écrits II, Gallimard, Paris, 2001, nํ 356, pp 1527-1548.

FRASER, Nancy (1981) "Foucault on Modern Power: Empirical Insights and Normative Confusions". En Unruly Practices: Power, Discourse, and Gender in Contemporary Social Theory, Minnesota University Press, Minnesota, 1989, pp 1734.

HABERMAS, Jürgen (1973) "Herbert Marcuse" (tr. de M. Jiménez Redondo). En Perfiles filosófico-políticos, Taurus, Madrid, 1984, pp 227-296.

(1980) "Modernity- An Incomplete Project". En FOSTER, Hel (Ed.), The AltiAesthetic. Essays on postmodern culture, Bay Press, Washington, 1987, pp 3-15.

(1981a) Teoría de la acción comunicativa I. Racionalidad de la acción y racionalización social (tr. de M. Jiménez Redondo), Taurus, Madrid, 1999.

(1981b) Teoría de la acción comunicativa II. Crítica de la razón funcionalista. (tr de Manuel Jiménez Redondo), Taurus, Madrid, 1999.

(1984) "Apuntar al corazón del presente" (tr. de A. Bonano). En COUZENS HOY, David, Foucault, Nueva Visión, Buenos Aires, 1988, pp 119-124.

(1985), El discurso filosófico de la modernidad (tr. de M. Jiménez Redondo), Taurus, Madrid, 1993.

(1985b) The Philosophical Discourse of Modernity (tr. de F. Lawrence). The MIT Press Cambridge, Massachusetts, 1987.

(1988a) "Heidegger: obra y visión del mundo. Contribución a la controversia sobre Heidegger desde una perspectiva alemana" (tr. de M. Jiménez Redondo) en Identidades nacionales y postnacionales, Tecnos, Madrid, 2007, pp 15-66.

(1988b) Pensamiento postmetafísico (tr. de M. Jiménez Redondo), Taurus, México DF, 1990.

(1999), "Una vez más: Sobre la relación entre teoría y praxis" (tr. de L. Díez). En Verdad y justificación. Ensayos filosóficos, Trota, 2002, Madrid, pp 307-320.

(1992) Facticidad y validez (tr. de M. Jiménez Redondo), Trota, Madrid, 2005. 
(2004) "¿Tiene todavía alguna posibilidad la constitucionalización del derecho internacional?" (tr. de J. L. López de Lizaga). En El Occidente escindido. Trotta, Madrid, 2006, pp 113-187.

GOFFMAN, Erving (1961), Internados: ensayos sobre la situación de los enfermos mentales, Amorrortu, Buenos Aires, 1970.

LEGRAND, Stéphane (2004) "Le marxisme oublié de Foucault", Actuel Marx, 36, pp 27-43.

MACEY, David (1993) Las vidas de Michel Foucault (tr. de C. Martínez Gimeno), Cátedra, Madrid, 1995.

MILLER, James (1993) La pasión de Michel Foucault (tr. de O. Luis Molina S.), Andrés Bello, Santiago de Chile, 1996.

SANTANA PÉREZ, Juan Manuel, PÉREZ RODRíGUEZ, Antonio (1999) "Habermas y Foucault: Modernidad, Posmodernidad y teoría de la Historia", Revista Vegueta, № 4, pp 103-116.

VOIROL, Olivier (2006) "Crítica genealógica y crítica normativa" (tr. de H. Cardoso) en CUSSET, Yves, HABER, Stéphane, Habermas y Foucault. Trayectorias cruzadas, confrontaciones críticas, Nueva Visión, Buenos Aires, 2007, pp 127-148. 